\title{
Claude Lefort e o Humanismo Cívico: os cursos da École des Hautes Études en Sciences Sociales
}

Claude Lefort et l'humanisme civique: les cours à l'École des Hautes Études en Sciences Sociales

Newton Bignotto

Universidade Federal de Minas Gerais | Minas Gerais | Brasil

\section{RESUMO}

O texto aborda o tema do "humanismo cívico florentino" a partir dos cursos que Lefort proferiu na École des Hautes Etudes en Sciences Sociales na segunda metade dos anos 70 do século passado. Nosso objetivo é mostrar que esse tema, que havia sido fundamental na elaboração das reflexões do autor sobre Maquiavel nos anos anteriores, foi uma ponte para suas reflexóes posteriores sobre questôes como a da democracia e do surgimento do Estado Moderno.

\section{PALAVRAS-CHAVE}

Claude Lefort; Humanismo cívico; EHESS; Estado moderno.

\section{RÉSUMÉ}

Le texte analyse le thème de « l'humanisme civique florentin » en partant des cours qui Lefort a donné à l'École des Hautes Etudes en Sciences Sociales dans la seconde moitié des années soixante-dix du siècle dernier. Notre objectif est de montrer que cette question, qui avait joué un rôle déterminant dans la préparation de ses réflexions sur Machiavel au cours des années précédentes, a été un point de départ essentiel pour ses réflexions ultérieures sur des questions telles que la démocratie et l'émergence de l'État moderne.

\section{MOTS CLEFS}

Claude Lefort; Humanisme civique; EHESS; État moderne. 
A relação de Claude Lefort com a temática do humanismo cívico data do período de elaboração de seu livro Le travail de l'œuvre. Machiavel (Lefort, 1972). Como ele declarou mais tarde: "foi a leitura de Maquiavel que nos fez reconhecer os caracteres singulares da sociedade florentina e do discurso humanista no começo do Quattrocento" (Ibid., p. 255). No curso dos anos 70 do século passado, ele voltou a se interessar pelo tema dessa feita guiado por seu desejo de explorar a questão da relação entre o nascimento da ideologia, ou das ideologias modernas, e as transformações sofridas pelas sociedades ocidentais ao longo da formação da modernidade. De maneira simplificada, podemos dizer que seu projeto à época era o de pensar o humanismo cívico como um primeiro momento da modernidade no qual a classe dirigente florentina firmou seu domínio sobre a cidade associando à posse dos meios econômicos um discurso de justificação de seu próprio poder (Ibid., p. 252). Lefort vê nascer naquele momento, que ele localiza entre os anos 1378 (Revolta dos Ciompi) e I434 (tomada do poder pela família Medici), "uma concepção racionalista e universalista da política", que estará no centro da modernidade política. Discurso e forma de dominação se entrelaçam, segundo ele, de uma forma impossível de ser encontrada na Idade Média com sua prevalência de uma "representação teológica do mundo".

Como alerta-nos Lefort, seu projeto não era o de um historiador, interessado em deslindar os passos de constituição de um conceito ou de uma ideia. É verdade que foram os historiadores os primeiros a chamar sua atenção para o que ocorrera em Florença no começo do século xv. No entanto, ele não pretende se implicar num projeto de natureza historiográfica. Partindo dos avanços da pesquisa histórica, ele quer compreender os vínculos entre as transformaçôes de uma sociedade em direção à modernidade e suas representações. Seria talvez razoável pensar que nosso autor adota o conceito marxista de ideologia e se serve dele para levar a cabo sua investigação. Nada mais estranho, no entanto, à démarche lefortiana do que essa forma de proceder. De fato, ele recorre à Marx e, a seu ver, isso era algo inevitável. Mas não o faz porque acredita poder encontrar nele um conceito pronto do que é a ideologia. Recorrer a Marx é importante porque através desse procedimento ele pensa poder melhor esclarecer a natureza do fenômeno que o interessa. Para Marx, afirma Lefort: "A ideologia tomada em sentido restrito, parece constituir o conjunto das representaçôes que a classe dominante forma para fazer crer na legitimidade e na necessidade de sua dominação e esconder a si própria os fundamentos dessa dominação" (Lefort, 1972, p. 27I). Para Lefort não se trata de abandonar simplesmente essa definição, que aponta para um aspecto importante da forma de existência das sociedades capitalistas modernas, mas sim de pensar seus limites à luz do que o surgimento do que o humanismo cívico pode nos ensinar. 
Dizer assim que o humanismo foi a ideologia da classe dominante florentina serve para mascarar tanto a dinâmica de formação do humanismo quanto o caráter do fenômeno ideológico. Lefort faz um percurso complexo no qual interroga tanto o aparecimento dos textos, que fazem da imitação do passado greco-romano sua mola de criação, quanto dos efeitos que a apropriação do passado produziu na sociedade italiana do Renascimento. Nesse sentido, cabe dizer que o humanismo foi ao mesmo tempo um fenômeno historicamente determinado e um fator determinante da transformação ocorrida na Europa no começo da modernidade (Ibid., p. 284). Por isso, não basta interpretar os textos como sinal de uma mudança, mas compreender que a constituição de um discurso como aquele dos humanistas alterou a imagem que a sociedade da época tinha da relação social. Servindo-se da obra de Eugenio Garin", Lefort afirma: "Que as exigências do saber compōem com as do agir até o ponto de ser desacreditado o ideal da vida contemplativa, que a imagem do cidadão associa a participação nos negócios públicos e no trabalho ao estudo das humanidades, que se afirma a ideia de uma cultura universal e de uma cidade livre, eis o que caracteriza a revolução realizada em Florença”.

Seguindo o procedimento analítico de Garin, Lefort conclui que o historiador é levado a subtrair o humanismo do campo da ideologia por situar sua formação no momento em que a sociedade florentina escolheu uma via que a liberou das amarras da Idade Média. Pensamento revelador de uma diferença e de uma identidade com um passado distante, ele não teria sido capaz de servir de esteio da nova formação social se fosse apenas uma forma de ocultação do real. Ora, para Lefort esse é apenas um dos pontos de vista a partir do qual é possível estudar o aparecimento do pensamento humanista. Para ele, "a verdade dos studia humanitatis nunca se reduziu à exploração dos autores antigos e ao ensino das línguas-modelo" (Lefort, 1972, p. 284). Ponto essencial da constituição de uma linguagem política da modernidade, ele também foi o lugar de alargamento da compreensão que a sociedade da época tinha da atividade política. Estudar o nascimento das ideologias por meio da investigação do surgimento do humanismo italiano significou para Lefort levar a cabo uma démarche complexa e rica constituída pelo entrelaçamento entre os estudos de caráter historiográfico, a análise dos textos e a investigação das transformações sociais e políticas pelas quais a Europa passou no curso do Renascimento. Lefort sintetizou essa percepção magistralmente um artigo publicado postumamente. "Digamos de forma tão breve quanto possível - afirma ele — que a ética política, a ética do comércio, a ética

I Embora Lefort não faça referência direta aos textos consultados, podemos remeter a dois escritos do historiador no quais a problemática tratada aparece de forma explícita. Eugenio Garin. L'umanesimo italiano. Roma: Laterza, 1986; Scienza e vita civile nel Rinascimento italiano. Roma: Laterza, I985. 
do conhecimento se confundem, enquanto se impõe a ideia seja da superioridade da vita activa sobre a vita contemplativa, seja de uma igual dignidade entre uma e outra" (Lefort, 2013, p. 62).

\section{Lefort e os historiadores}

Recentemente alguns historiadores voltaram a analisar o surgimento do humanismo italiano associando suas análises aos trabalhos de Hans Baron e ao fato de que eles acreditam que o historiador, junto com Garin, ajudou a forjar uma ideia idealizada do movimento de ideias surgidas no final do século xIv, começo do século XV. Na esteira das críticas feitas por Seigel (Seigel, I968) a Baron ainda nos anos 6o, autores como Mikael Hörnqvist (Hörnqvist, 2000, pp. I05-I42) e James Hankins (Hankins, 2000, pp. I43-I78) procuraram apontar para a fragilidade das teses que fazem do humanismo cívico um dos constituintes centrais de construção do pensamento político moderno. Para Hörnqvist o chamado humanismo cívico é resultado de uma dupla mitologia. De um lado a mitologia criada pelos próprios humanistas para descrever a sociedade na qual viviam e ocupavam cargos de poder; de outro lado a mitologia criada por Baron em seus estudos. Dessa maneira, acredita o estudioso, é possível "mudar nosso foco do estudo das ideologias para o estudo da construção de mitos" (Hörnqvist, 2000, p. I42). Na mesma direção, Hankins afirma que um autor como Bruni não pode ser descrito como "um homem com um profundo comprometimento ideológico com uma constituição republicana" (Hankins, 2000, p. I77), o que, aos olhos dos intérpretes, faz com que a própria designação do humanismo como cívico deva ser posta em questão. Para ambos, trata-se de um pensamento retórico, ligado às tópicas retóricas da Antiguidade, o que compromete a seus olhos a coerência argumentativa dos textos.

Voltando nosso olhar para os trabalhos de Lefort, é possível apreciar o sentido de sua démarche, por vezes sinuosa e exigente. Diferentemente dos estudiosos citados, ele nos ajuda a ver que não basta recorrer a uma ideia do que seja a ideologia sem definir seu estatuto teórico e, sobretudo, sua forma de instauração como representação do social e do político. Da forma como o conceito é usado pelos historiadores, ela é signo de falsa representação e, por isso, pode se casar com a retórica, que também ela forja processos que são supostamente de ocultação do real da política. Ora, o que salta aos olhos, é o fato de que as críticas feitas pelos estudiosos citados aos trabalhos de Baron escondem uma concepção da política que opera a partir da cisão entre realidade e discurso e, sobretudo, entre discurso verdadeiro e discurso falso. Não é preciso dizer que a combinação de uma concepção fluida do que é a ideologia com o horror da retórica é constitutiva de uma concepção da política como do terreno do embate entre oponentes, 
que reconhecem o debate racional como forma por excelência do conflito. Com isso, a política é reduzida a um de seus aspectos e expurgada de seus elementos simbólicos e imaginários, que para Lefort são essenciais para a compreensão da vida em comum.

O Humanismo cívico nunca deixou de interessar Lefort, embora ele nunca tenha levado a cabo o projeto de escrever um livro exclusivamente dedicado à Florença. $\mathrm{O}$ tema reaparece em vários momentos de sua obra, ora ligado à Maquiavel, ora à questão da modernidade política, ora ainda à tópica do republicanismo. Em um texto de seu livro Écrire. À l'épreuve du politique (Lefort, 1992; tradução brasileira de Eliana de Melo Souza, 1999), ele começa falando das origens do republicanismo francês, para concluir que, se quisermos compreender o republicanismo moderno, devemos voltar nosso olhar para a Florença renascentista. A tese do vínculo entre o humanismo cívico renascentista e o pensamento do século XVIII já estava presente em seus estudos anteriores, quando nosso autor mostra que o humanismo foi "historicamente determinante" até o século XIx (Lefort, I979, p. 286). Lefort não abandona o eixo de suas considerações anteriores sobre a natureza ideológica do humanismo italiano. Para ele "o republicanismo florentino é uma ideologia da conquista” (Lefort, 1999, p. 192), no que ele antecipa as pesquisas de autores como Quentin Skinner e Mikael Hörnqvist, que insistiram na dimensão expansionista da herança romana reivindicada pelos humanistas. Mas foi a recuperação do papel do humanismo cívico na formação do republicanismo moderno que lhe chamou a atenção no momento em que mergulhou seu olhar no movimento de constituição da modernidade política. Certamente suas análises foram influenciadas pela leitura dos trabalhos de Pocock, mas é preciso lembrar que os dois autores não partilhavam a mesma concepção da política e da democracia, quando escreveram seus trabalhos. Em particular, é preciso notar que Lefort é um pensador da divisão do corpo social e do conflito, o que o leva a afirmar que: "A república não poderá assegurar a harmonia da sociedade, pois está sempre dividida e é uma divisão que só pode ser entre dominantes e dominados" (Ibid., p. 193). Se ele concorda com Pocock no que diz respeito ao papel das teorias do regime misto na formação do republicanismo renascentista, ele segue outro caminho, quando privilegia a importância das lutas políticas na constituição do espaço institucional. Não se trata de negar o papel da vida institucional, mas de ancorá-la no terreno da divisão constitutiva e inultrapassável do corpo político.

\section{Os seminários da EHESS}

Entre os textos dos anos 70 e aqueles dos anos 90 há uma mudança de perspectiva no estudo do Humanismo cívico italiano, mas também muitos elementos de permanência. Lefort continua interessado em explorar os domínios dos funda- 
mentos do que chamou de "político" em associação com uma investigação sobre o nascimento e o desenvolvimento da democracia moderna. Como nunca reduziu tal regime a uma expressão de sua organização institucional, a referência aos humanistas continuou sendo o signo da compreensão da política, que escapa dos muitos caminhos simplificadores propostos tanto por cientistas políticos institucionalistas, quanto por pensadores marxistas aferrados a um paradigma ossificado de leitura das sociedades modernas e contemporâneas. Dito isso, é preciso levar em conta que o olhar de Lefort sobre o humanismo cívico se transformou, ao sabor da ampliação de seus interesses e dos muitos diálogos que estabeleceu com outros pensadores, com as artes e com os acontecimentos de seu tempo.

Não é nosso objetivo analisar em profundidade todas as referências aos humanistas italianos presentes na obra lefortiana. Partindo das considerações anteriores, que atestam a importância do tema ao longo de sua trajetória, vamos procurar mostrar como a mudança na perspectiva de análise do tema acompanha a transformação das preocupações teóricas do autor, ao mesmo tempo em que aponta para a abertura de um diálogo cada vez mais amplo com os que se interessaram por questóes como a da democracia contemporânea, suas origens e seus fundamentos. Uma forma interessante de estudar as transformaçôes internas do pensamento lefortiano, sobretudo no tocante a seus estudos sobre o humanismo, é recorrer aos cursos que proferiu nos primeiros anos de seu magistério na École des Hautes Études en Sciences Sociales (EHEss) que têm por tema exatamente o humanismo florentino. ${ }^{2}$ Proferidos ainda na década de 70, mas depois da publicação de seu estudo sobre Maquiavel, os cursos apontam para os caminhos que Lefort começa a trilhar e apontam para a questão mais ampla da formação do Estado moderno.

O primeiro seminário dedicado ao tema foi anunciado com o título: "A gênese do Estado moderno e a instituição do social" no ano escolar de 1976-1977. Lefort começa dizendo que seu percurso terá como referência: "Florença no final do Trecento e no começo do Quattrocento" (Lefort, 1976-1977, p. I). O seminário tem início com a reafirmação das teses defendidas tanto em seus projetos de pesquisa quanto no texto ao qual fizemos referência. $\mathrm{Na}$ esteira de Marx, ele reafirma a tese de que o humanismo foi uma ideologia, ainda embrionária, do que seria a ideologia da burguesia em sua pretensão de se constituir como um discurso universalista sobre a política (Ibid., p. 2). Mas mais importante para ele, nesse momento, parece ser a constatação de que com os humanistas "vemos se instituir uma nova sensibilidade ao tempo, ao espaço, um novo sentido, diria, da integridade que se manifestará tanto na representação da distância e da diferença do passado ao

2 Esse material faz parte dos arquivos Claude Lefort depositados na EHEss. Agradecemos a Gilles Bataillon que nos facultou o acesso ao material e permitiu o uso para esse trabalho. 
presente quanto da diferença do leitor ao autor ou ao texto..." (Ibid.). Florença é, a seus olhos, o local de uma experiência que permite-nos interrogar a função simbólica do poder e as diversas articulações que constroem uma sociedade em seu vínculo com o saber, com a lei e com a cultura. Lefort esclarece sua démarche quando afirma que, ao estudar Florença, o que ele procura ressaltar "é uma inteligibilidade que esclareça os fenômenos da política, os fenômenos da cultura e a ideologia em geral" (Ibid., p. 3). De forma mais ampla, ele acredita que Florença "ensina a pensar o político" (Ibid., p. 5).

Ao anunciar seus objetivos, Lefort estava consciente das dificuldades que o esperavam, sobretudo por ter feito de uma sociedade particular, num momento particular, um objeto privilegiado de estudos. Longe de fugir dos problemas postos por sua démarche, eles os enfrenta recorrendo à crítica do que ele entende ser a limitação da sociologia política de seu tempo. Ao mesmo tempo, ele lembra a maneira como Merleau-Ponty criticava as diversas formas de objetivismo, para afirmar que toda organização social ou política só pode ser estudada e compreendida se formos capazes de mostrar que as representações constituem uma parte fundamental das práticas sociais e não podem ser delas separadas.

\section{O Estado moderno}

Ao iniciar seu seminário, Lefort parecia conduzir seus auditores para uma análise dos acontecimentos que marcaram a vida italiana no começo do quattrocento, mesmo se nos mesmos moldes dos textos que comentamos antes, ele alerte para o fato de que seu projeto não possui um caráter historiográfico. De fato, ele não se lança ao longo do seminário em um estudo detalhado das condições históricas do surgimento do humanismo, mas longe de se concentrar no período que ele delimitou para sua investigação, ele faz uma série de considerações de cunho teórico, que nos ajudam a compreender a natureza de seu projeto intelectual naquele momento. De um lado, ele consolida algumas tópicas de seu pensamento, que já haviam surgido em seus escritos anteriores, mas que recebem agora uma formulação mais decantada e que parece sinalizar para uma mudança de rumos que, longe de negar o percurso teórico empreendido até então, o aprofunda em novas direções. Cabe lembrar que, nesse momento, Lefort já publicara sua grande obra sobre Maquiavel e já dera a conhecer as linhas mestras de sua filosofia política. Ao retornar a temas e problemas que abordara antes, ele assegura uma transição em direção às questôes que estarão no coração de sua reflexão a partir de então, notadamente, ele investe na consolidação de uma teoria sobre a democracia moderna que já estava anunciada, mas não desenvolvida, em seus escritos dos anos anteriores. 
O primeiro ponto importante em sua démarche são suas considerações sobre a relação entre a instituição do social e sua representação. Nos anos 50, Lefort se interessou pela cena política internacional, o que podemos entrever em seus escritos para a revista Socialismo e Barbárie. Num primeiro momento, o diálogo com a tradição marxista o conduziu a pensar a revolução e o papel do proletariado em relação com a crítica que fizera nascer a revista, que se pretendia não apenas um órgão de debates, mas uma verdadeira organização de lutas comandada por uma vanguarda, à distância tanto do Partido Comunista francês quanto do partido trotskista ao qual ele pertencera. Lefort não permaneceu muito tempo ligado ao projeto, que lhe parecia cada vez mais distante da realidade, mas é um fato que seu diálogo com Marx, (mas não necessariamente com os militantes marxistas), foi determinante para sua trajetória de crítica do totalitarismo burocrático e para sua formulação de uma teoria da democracia moderna (Lefort, 2007b, pp. 237245). No momento em que lecionou pela primeira vez na EHEss sobre o tema do humanismo, a confluência entre suas preocupaçôes com a natureza totalitária do regime soviético e sua interrogação sobre a democracia se uniram num esforço de pensamento que, sem pretender realizar uma síntese, como aquela operada por pensadores como Hegel e outros, aponta para a convergência dos conceitos que procuram esclarecer a natureza do que Lefort nomeia como "o político".

Nessa lógica, ao romper com uma certa tradição que separa a representação da instituição do social, Lefort aponta para um caminho que o afasta de alguns intérpretes atuais do humanismo cívico, como Alison Brown que fala em "desmascarar o republicanismo do Renascimento" (Brown, 2000, pp. 179-I99), mas também aponta para uma filosofia política inovadora em muitos aspectos. No tocante ao problema da representação, ele nega que uma sociedade histórica possa separar seu processo de instituição daquele de representação. Na verdade, para Lefort na medida em que se institui, a sociedade gesta uma representação de si mesma que não pode ser pensada nem num antes nem num depois da própria instituição contínua do social. A isso nosso autor chama de "enigma de sua instituição". Enigma, diz ele, pela impossibilidade na qual se encontram as cidades de organizar e dominar sua origem e tudo que a ela se remete: relações sociais, organização das crenças e das condutas sociais. "Para dizer de outra forma - pontua Lefort - toda sociedade na medida em que ela não pode se representar sua origem, nem sua identidade, é presa em uma divisão com relação a ela mesma, quer dizer que ela tende a se organizar a partir de um além da representação, de

3 A esse respeito são esclarecedores os textos que Lefort publicou na segunda metade dos anos 70 e que mostram sua preocupação com o problema dos totalitarismos e da instituição da democracia como um regime de conflitos. Lefort, Claude (2007a). Le temps présent. Écrits 1945-2000, pp. 217-421. 
um além do discurso social, que não poderia existir no visível e que, ao mesmo tempo, dá sentido, fornece uma determinação a tudo o que se agencia no visível" (Lefort, 1976-1977, p. I0).

Essa maneira de compreender o processo de instituição de uma sociedade mostra a ingenuidade dos estudiosos de Florença, que acreditam poder apontar nos discursos sobre a cidade o sinal de uma falta e mesmo de uma manipulação do discurso. Nessa lógica, existe um movimento de formação objetiva da sociedade e um discurso sobre a cidade. Esse último é, no caso do humanismo cívico florentino, para intérpretes como Hankins, o resultado de um engano e da vontade de enganar os cidadãos por meio de uma representação do real que nada mais faz do que esconder sua face verdadeira. O que Lefort nos ajuda a ver não é o caráter não ideológico do humanismo. Por diversas vezes ele se referiu ao humanismo como a uma ideologia. O que ele mostra é que a criação de um discurso não é um segundo momento da criação de uma cidade ou de novas instituições. Não há como separar analiticamente no tempo a criação institucional e o discurso que a acompanha. A representação é parte da criação e da própria política. É por não compreender essa realidade que os autores liberais demonstram um verdadeiro horror à retórica, que lhes parece o exato oposto da transparência, que deve presidir a vida nas sociedades democráticas. Para Lefort, o humanismo é parte integrante da criação da sociedade florentina e de sua representação, por isso não pode ser separado do momento em que nasceu e pode, ao mesmo tempo, estar no início de um processo de longa duração de instituição do pensamento político e das sociedades modernas.

É nessa lógica que, antes de voltar sua atenção para os humanistas, o pensador francês decide esclarecer o que ele chama de Estado moderno e quais são as características que o definem e que poderiam estar ligadas ao aparecimento das sociedades mercantis modernas. Um primeiro traço que para ele define um Estado na modernidade é o território. Essa afirmação não é para ele nada óbvia, pois não se refere apenas ao fato de que uma dada sociedade precisa existir num dado lugar e tempo, mas se refere ao conjunto de relações que se tecem entre a população, o território e o poder. Isso se dá, segundo Lefort, porque "o espelho territorial e o espaço social são constituídos como espaço unificado, como espaço circunscrito, em virtude do destacamento do poder que, de sobrevoo, detém de alguma maneira, o ponto de vista, o ponto virtual de domínio e leitura do conjunto" (Lefort, 1976-1977, p. I3). De forma lapidar, nosso autor afirma: “O poder político aparece como fundador da sociedade na medida em que encontra seu fundamento na sociedade" (Ibid.). Lefort mostra que em sociedades nas quais o poder não é vivido como parte da sociedade ela mesma, o despotismo é a forma por excelência da organização social. Isso se dá pelo fato de que o poder 
se apresenta como emanação de uma ordem externa à sociedade enquanto tal. As divisões internas das sociedades e seus conflitos se apresentam como externas à ação do poder e, por isso, externas à ação no interior da sociedade.

Essas considerações são importantes para as análises que Lefort leva a cabo sobre o totalitarismo, mas não é isso que o interessa de forma mais ampla em seus cursos. Ao contrário, é a diferença entre as sociedades modernas e as sociedades regidas por um outro conjunto de referenciais, que o levam a pensar o humanismo como momento inaugural do Estado moderno. Ele se define, segundo ele, pela impossibilidade de assinalar a origem da lei, do conhecimento e da divisão social. Com essa observação, Lefort inicia uma crítica ao marxismo que, acentuando o conflito de classes, pretende remetê-lo em sua dimensão essencial à disputa econômica. Como assinala o pensador, Florença tivera seu auge econômico muito antes das disputas que iriam marcar sua história política no início do século XV e expor a fratura social que a dominava. Chamando a atenção para o problema do surgimento do Estado moderno, ele não pretende negar o papel das relações econômicas, mas quer integrá-las num processo muito mais amplo do que aquele de uma luta entre grupos sociais antagônicos. É a natureza fundante do conflito e ao mesmo tempo a percepção de que ele não pode ser reduzido a apenas uma de suas dimensões que distancia Lefort do marxismo, com o qual, no entanto, ele mantém um diálogo fecundo ao longo de toda sua obra.

Para pensar a natureza do Estado, é preciso lembrar que "o poder político ao mesmo tempo em que ele se destaca da sociedade, só se define por meio da relação que entretém com ela ou que nela encontra seu fundamento" (Lefort, 1976-1977, p. 19). Dessa maneira, para entender a singularidade do poder político dos Estados modernos, é mister reconhecer que ele porta em si a marca da busca pela universalidade de seus fundamentos e a fragilidade decorrente do fato de que ele é fruto da contingência que o instaura e que se encontra no interior mesmo da sociedade que o viu nascer. Poder e sociedade, Estado e sociedade estão entrelaçados na modernidade de tal maneira que é impossível pensar um dos polos sem remeter ao outro. Só há Estado porque a autoridade política exerce seu poder à distância da sociedade (Ibid., p. 23). Essa por sua vez reconhece a si mesma pela afirmação da distância que a separa do poder político ativo. Lefort critica assim os pensadores que tendem a só ver no Estado moderno seu aspecto repressivo. Embora não o cite, é possível que estivesse pensando em Foucault nesse momento (Ibid.). O que lhe interessa é que ao se tornar visível por meio de suas ações, o poder político desvela sua contingência e, portanto, o fato de que ele se institui por meio da busca de uma posição universal de legitimação, mas ela não a porta para todo o sempre e nem pode ocultar da sociedade que lhe é coetânea, sua fragilidade essencial. 
Nesse processo de constituição do poder, que podemos pensar por meio da referência à afirmação do poder da oligarquia florentina no começo do século xv, surge a necessidade de afirmação de um discurso. Discurso do poder, diz Lefort, "que tende a tornar inteligíveis e legítimas suas decisōes" (Ibid., p. 20). De um ponto de vista moderno, mesmo se há algum anacronismo em dizer isso, os discursos de humanistas como Salutati e Bruni não tinham nada de exterior à constituição do poder ao qual serviam. Para Lefort não há distância entre o estabelecimento do poder e a busca de um discurso de justificação de seus atos. Se isso ocorre é porque não estamos nas águas da modernidade e muito menos do republicanismo e da democracia. Os intérpretes liberais de hoje não compreendem a dimensão instituinte do poder e menos ainda o papel que os discursos que ele gesta têm na formação do Estado e da sociedade modernas. Não veem além disso que a afirmação de um discurso do poder "ao delimitar um campo político libera o não político enquanto tal" (Ibid.). Ou seja, ao falar, o poder se torna visível, expõem-se à crítica e ao ataque dos que estão sob sua alçada. O combate político não é evitado pela fala do poder, ao contrário, ele é possível exatamente porque o poder procura se justificar e fundamentar suas ações por meio de discursos. Criticar, nessa lógica, os humanistas pelo recurso à retórica é o mesmo que criticá-los por terem aberto as portas para a modernidade. Os autores que como Hankins e Seigel descreditam a retórica dos humanistas, são obrigados a negar-lhes a importância na criação do caminho que levará ao mundo moderno. Lefort parte em outra direção.

\section{Retorno ao Humanismo florentino}

Ao enunciar a continuidade do seminário, que se iniciou com as considerações sobre a ideologia e sobre o nascimento do pensamento político moderno, Lefort afirma querer abordar "o problema do poder e do nascimento do humanismo e da ideologia em Florença na passagem do trecento ao quattrocento" (Lefort, 19761977, p. 27). Podemos falar aqui de um retorno, pois não podemos nos esquecer que, poucos anos antes, ele havia publicado sua obra sobre Maquiavel que, como sabemos, se nutriu de uma leitura dos humanistas italianos e de suas relaçóes com o surgimento do pensamento político moderno. Tomando em consideração esse fato, é razoável supor que o pensador francês não pretendia repetir suas análises anteriores, mas que, ao contrário, partia delas para avançar sua reflexão sobre novas questóes.

Isso fica evidente pela démarche do seminário. Lefort diz aos auditores que pretende esclarecer como ele mesmo chegou ao tema que anunciou e inicia sua apresentação falando de pontos essenciais de sua interpretação da obra de Maquiavel. Os que a conhecem, sabem que ela termina com uma análise das noções de 
"obra" de "ideologia" e de "interpretação" e que, nessa última parte, o pensador se inquire justamente sobre as relações de Maquiavel com o humanismo à luz da ideia de que "O pensamento de Maquiavel se elabora na matriz do humanismo político ao mesmo tempo em que adquire sua identidade ao se afastar dela" (Lefort, 1972, p. 77I). Sua preocupação com o fenômeno da ideologia, que data dos anos cinquenta do século passado, encontrou no Renascimento italiano um terreno fértil de inquirição. Os seminários que estamos examinando demonstram que esse foi um caminho frequente da reflexão lefortiana.

A apresentação das ideias de Maquiavel feita no seminário não altera em nada as conclusôes às quais ele havia chegado em sua grande obra. Ele destaca, sobretudo, o papel essencial dos conflitos na vida política e como eles foram importantes na construção da grandeza romana, fato que parece ter sido ignorado pelos humanistas que antecederam o secretário florentino. O objetivo de Lefort, no entanto, não é o de fazer ele mesmo a crítica do humanismo, tarefa que lhe parece sem interesse, mas de mostrar como nas relaçôes entre Maquiavel e seus antecessores se delineia um conflito que opõe uma forma de saber e a ideologia do grupo dominante de Florença. De forma direta ele afirma: "Assim, eu diria brevemente que aos meus olhos essa crítica se dirige contra uma ideologia" (Lefort, 1976-1977, p. 35). Ele está se referindo aqui ao embate entre Maquiavel e os humanistas, mas essa abordagem tem um alcance maior na medida em que nos permite compreender como de uma única fonte é possível forjar discursos de natureza muito diversas. Seu novo ponto de partida, no entanto, não se resume a recuperar aspectos das teses que já apresentara antes, mas sim em desenvolver uma temática que sempre o intrigou. Desse ponto de vista a primeira parte do seminário se esclarece quando ele conclui que "O discurso de Maquiavel é contrário a um discurso que já poderia ser descrito como moderno" (Lefort, I972, p. 36). O conflito entre o secretário florentino e seus predecessores é um conflito moderno, que se desenvolve tanto no terreno da ideologia quanto no da filosofia e da crítica humanista. Voltar a ele faz parte de um projeto maior de interpretação da modernidade e do nascimento do pensamento moderno e não apenas de uma rememoração do percurso que Lefort empreendeu nas décadas de cinquenta e sessenta do século vinte.

Fiel à démarche de investigação filosófica que estabelecera em suas obras anteriores, Lefort passa então a se dedicar a um estudo detalhado de alguns aspectos da obra de Hans Baron: The crisis of the early italian Renaissance. ${ }^{4}$ Como em outros de seus trabalhos, Lefort expõe com minúcias as teses do historiador,

4 Baron, Hans. The crisis of the early italian Renaissance, Princeton: Princeton University Press, 1966. 
mas isso não significa que ele esposa suas ideias ou mesmo suas preocupações centrais. É preciso lembrar que o pensador francês não pretende fazer o trabalho dos historiadores e nem se envolver em polêmicas de natureza historiográfica. ${ }^{5}$ Seguindo Baron, Lefort desvela, aos poucos, suas próprias teses e o caminho que pretende seguir para demonstrá-las. Assim, ele se preocupa em primeiro lugar com o significado da conversão dos humanistas, termo genérico, que se refere a todos os que no Renascimento se preocuparam com questóes ligada à herança da Antiguidade, em "humanistas cívicos", que será um dos termos marcantes dos escritos de Baron. O pensador francês, no entanto, recupera os argumentos de Baron não para participar do debate que se seguiu à publicação do livro do autor entre os historiadores e nem para aquilatar a correção da tese segundo a qual é possível datar o aparecimento de um humanismo político no começo do quattrocento. O que interessa Lefort é a constituição de uma nova arena política e de um novo discurso sobre a política. Expondo com cuidado o percurso de Baron, Lefort nota que ele se deixa aprisionar no dilema de fazer o humanismo político decorrer do humanismo em geral ou de apontar para os anos inicias do século XV como o momento de aparecimento de um humanismo florentino. A tese principal de Baron, a saber, que o humanismo cívico nasceu em Florença numa data precisa em textos específicos, tese que provocou uma torrente de críticas, não interessa ao pensador, senão na medida em que ela abre as portas para sua própria reflexão sobre a natureza e o significado dos textos humanistas. De forma direta, ele afirma: "[...] toda essa revolução que se passa na virada do século deve ser recolocada em um quadro simbólico cuja transformação ocorre em outros níveis notadamente ao nível da divisão de classe, ao nível da divisão do poder e da sociedade e, portanto, não é uma outra elucidação da causalidade, não é em direção a isso que eu sigo". O aspecto mais controverso das teses de Baron simplesmente não está no centro das preocupações de Lefort, que parte das análises do historiador para aprofundar seus questionamentos sobre temas que há muito o habitavam: a divisão social, a natureza do discurso político, a fundação do corpo político, o surgimento da democracia.

Assim, quando Lefort se lança no estudo dos escritos e na carreira política de Coluccio Salutati e de Leonardo Bruni, ele está à procura de um esteio para suas hipóteses a respeito do surgimento da política moderna, termo que ele mesmo tentará definir, ou precisar, ao longo de suas investigações. Sua estratégia argumentativa começa a se desvelar quando ele afirma, referindo-se aos discursos do chanceler de Florença, que: "Durante esse período, Salutati não deixará de agir, uma ação extremamente eficaz na escala europeia a ponto do grande inimigo de

5 Para um balanço dos debates sobre a questão do humanismo cívico ver: Hankins, 2000. 
Florença, Giangaleazzo, dizer que o senhor Coluccio, chanceler da signoria, lhe fez uma guerra mais eficaz com suas cartas do que todos os capitães florentinos com suas lanças" (Lefort, 1976-1977, p. 58). Lefort enxerga nos discursos dos humanistas florentinos a ferramenta ideal para se pensar como se opera a fundação de um novo corpo político e da narrativa que o insere na história. Olhando para Florença, os acontecimentos que a sacodem no Renascimento e como seus humanistas souberam produzir uma imagem do que se passava com a cidade, ele acredita poder caminhar na direção da elucidação de um dos percursos de formação da modernidade política.

Florença é, assim, apresentada ao mundo como "o povo príncipe", detentora de uma idealidade que a faz ser invejada e ao mesmo tempo imitada por todos que desejam alcançar suas glórias e realizações. Descendente direta dos romanos, ela herdou não apenas suas instituições, mas principalmente o que hoje chamaríamos de seus valores. A narrativa da história da cidade passa a fazer parte da natureza mesma da cidade. Referindo-se à busca empreendida pelos humanistas florentinos das origens da cidade, Lefort afirma; "Vemos muito bem como a história funciona miticamente” (Ibid., p. 65). Cabe, portanto, voltar aos textos nos quais essa estratégia se mostra claramente. Dentre eles, a Laudatio Florentinae urbis de Leonardo Bruni ocupa um lugar especial (Bruni, 1968). Calcado em um texto de Aristides, a Laudatio oferece um material precioso para a compreensão da estratégia dos humanistas florentinos para criar uma nova narrativa sobre as origens da cidade e sua natureza.

Baron já observou que a imitação dos textos antigos é em grande medida uma operação formal. O que há de novo nesse discurso, sublinha Lefort, é "o laço que se estabelece entre uma representação da história, uma representação da ordem política e uma representação do espaço da cidade" (Lefort, 1976-1977, p. 73). No tocante ao sistema político, o que ressalta é o fato de que ele "é concebido como um conjunto de instituições e de ofícios que são agenciados de maneira estritamente racional, rigorosa, clara e de maneira a que cada instituição possa ser controlada pelas outras e que nenhuma instituição, nenhum ofício possa ser o local da tomada do poder" (Ibid.). Ora, essa descrição, como mostra Lefort, estava muito distante da realidade política da cidade. Longe de ter se tornado mais democrática no começo do século xv, Florença havia fortalecido o poder da oligarquia que, desde a revolta dos Ciompi, no final do século anterior, havia operado uma transformação dos poderes da cidade de tal maneira que eles ficassem cada vez mais concentrados nas mãos dos cidadãos mais ricos e influentes.

O que se assiste, portanto, naqueles anos que interessam Lefort, é ao mesmo tempo a consolidação de um poder, que não hesita em duplicar as instituições para poder governar, e a constituição de uma imagem da cidade, que contribuiu 
para a estabilização das novas instituições com suas novas regras. Como resume o pensador francês: "O que ressalta da Laudatio é não somente a representação de Florença como uma cidade particularmente bela, de fato particularmente bem constituída, é a representação dela como cidade perfeita" (Ibid., p. 79). Natureza, espaço e história se combinam para produzir a imagem de um corpo político que venceu todos os obstáculos para erigir na história a melhor cidade possível. $\mathrm{O}$ resgate da Antiguidade produz uma arma no presente contra os que poderiam pretender apelar para a história recente da comuna para reivindicar lugares no concerto dos poderes. Cidade concebida segundo critérios racionais e estéticos, Florença se abre para novos atores, desde que sejam eles mesmos os inovadores que elaboram uma redistribuição dos espaços e dos cargos nas instituições.

Desse ponto de análise, até onde aparentemente Lefort acompanhara Baron, ele se distancia, mostrando que desde o início seus objetivos eram diferentes daquele do historiador. Como em outros momentos de sua trajetória intelectual, ele se aproxima e se apropria da exposição e dos argumentos de outros intelectuais para melhor forjar sua própria filosofia política, que possui uma pauta e objetivos que muitas vezes estão distantes daqueles com quem dialoga. Aliás, esse modelo de criação do pensamento, Lefort remete a Maquiavel, que ele volta a analisar no curso dos seminários, justamente a partir da carta que ele endereça a seu amigo Vettori logo depois de ter terminado a redação d'O Príncipe. Lefort não pretende erigir Maquiavel em modelo de escrita filosófica, mas demonstra como o pensamento nasce muitas vezes de um comércio com o passado tornado presente. É porque é possível pensar no diálogo com o outro que o tempo pode ser abolido e a distância encurtada, para fazer no presente a operação de constituição de um novo discurso sobre o real.

É em torno da noção mesma de discurso que Lefort encaminha suas conclusóes. Voltando aos escritos de Bruni e de Salutati, ele mostra que o que nasce em Florença no século XV não é apenas uma nova forma de governo calcada em modelos da Antiguidade. Para ele "é o discurso ele mesmo que nasce", no sentido de que o aparecimento de um novo discurso sobre a cidade é ao mesmo tempo a produção de um novo poder. Como mostra Lefort: "Ora esse discurso do poder, eis que ao mesmo tempo, seu aparecimento marca o poder do discurso" (Lefort, I976-I977, p. 8I). Nesse ponto de sua argumentação, o pensador francês é obrigado a fazer um esclarecimento. A associação do discurso e do poder, a ideia de que ele "recobre" o poder, certamente lembra a seus auditores e leitores o interesse que Lefort tinha pelo fenômeno ideológico. Ora, como ele afirma: "Eu não digo nesse momento que nós estamos na ideologia, quer dizer no discurso que dissimula o poder" (Ibid., p. 82). Trata-se de algo que se avizinha da questão da ideologia, mas que, segundo ele, se encontra "aquém do fenômeno ideológico" 
e que, por isso, "eu deixo indeterminado o sentido que está aquém da conversão ideológica. A saber, esse discurso é um discurso de verdade, que se coloca sob o signo da verdade e que de uma certa maneira é o discurso de ninguém" (Ibid.).

Lefort passa, então, a investigar esse discurso, nascido em pleno Renascimento e que altera a maneira de compreender a natureza política das cidades. Para que ele pudesse ter a pretensão de ser "um saber", era preciso assegurar que seu objeto, a cidade de Florença, era ela mesma uma forma universal, uma "pátria" de todas as pátrias. Para compreender a eficácia dessa operação, é preciso, em primeiro lugar, observar que a "emergência do poder do discurso - que Lefort acredita ter detectado no período que analisa - enquanto esse discurso vem velar o objetivo do poder e se encontra proferido, pronunciado como se viesse de lugar algum, quer dizer proferido como discurso universal, discurso de verdade, discurso que se enuncia em nome da humanidade" (Ibid., p. 84). A universalização do discurso só é possível porque ele é um discurso histórico, que recria a narrativa da história das cidades, como já aludido, colocando-a, no entanto, sob a égide do universal. O importante inicialmente é reconhecer que "esse discurso histórico está profundamente ligado ao discurso político” (Ibid., p. 85). Essa ligação que intriga Lefort. Para ele, o retorno à Antiguidade é na verdade a criação da Antiguidade ela mesma. Colocada à distância, circunscrita em seus traços mais salientes, ela se torna ao mesmo tempo um objeto distante e próximo, na medida justamente em que pode renascer, ressuscitar, para usar o termo de Lefort (Ibid., p. 87).

O discurso histórico, que nasce com os humanistas no começo da modernidade, é diferente daquele do passado. Ao mesmo tempo em que instaura a política, apaga a distância com os autores do passado. O discurso dos humanistas é, nesse sentido, inteiramente moderno. Como afirma Lefort: "Em suma, é dessa distância nova ao passado, dessa distância construída a partir do presente, que surgiria a ideia de história" (Ibid., p. 94). Voltando seu olhar para os florentinos que ele havia investigado, ele afirma que eles se viam, como os modernos, "na história". A noção moderna de história se forja, portanto, ao mesmo tempo em que o discurso sobre a cidade procura se assentar sobre novas bases. Se se tratasse simplesmente de copiar o passado, não haveria necessidade de se colocar à distância dele. É porque a Antiguidade está morta que ela pode ser evocada pelo presente. "O lugar da história — diz Lefort — aparece como um lugar separado com relação a esse mundo, que formiga de acontecimentos de toda ordem e é um lugar que se pode ler numa primeira abordagem. Da mesma maneira, o político aparece como separado com relação ao que pode ser a luta de facções, as relações que se instalam de fato na cidade entre os homens, de onde a mudança de vestimenta" (Ibid., p. 97).

Florença é um polo importante para se compreender a política por que em sua 
história se cristalizaram vários fenômenos que depois estarão no centro de tantas experiências de criação de novos corpos políticos na modernidade. Ela remete a um ponto imaginário, ressurreição de um passado ideal, ao mesmo tempo em que permite a descoberta do histórico como o domínio no qual a política instaura seu regime de existência no tempo e que dele foge para constituir no além do tempo presente as origens que iluminam os traços definidores da cidade ideal.

Os seminários da EHEss dos anos 1970 fornecem um material importante para se compreender o desenvolvimento do pensamento de Lefort e suas transições. Ao retornar aos humanistas florentinos, ele fez mais do que rememorar sua trajetória. Ele nos mostra os laços que unem sua grande obra sobre Maquiavel com as reflexôes inovadoras sobre a democracia e o totalitarismo, que irão marcar seus escritos posteriores. Ao mesmo tempo em que suas referências aos autores do passado se veem reafirmadas e que seu método de trabalho se mostra em toda sua força, os seminários permitem compreender em ato o processo de produção de um saber que sempre se negou a se fixar em caminhos batidos da tradição. Eles mostram como Lefort, por vezes de maneira sinuosa, percorria caminhos e veredas em sentidos antes insuspeitos e como desse procedimento de exploração da história e dos discursos na história ele retirava o alimento para uma obra sólida e criativa que marcou a filosofia política contemporânea.

\section{Referências}

Brown, Alison (2000). "De-masking Renaissance republicanism", In James Hankins (Ed.), Renaissance Civic Humanism, Cambridge: Cambridge University Press, pp. I79-I99.

Bruni, Leonardo (1968). "Laudatio Florentinae Urbis", In Hans Baron, From Petrarch to Bruni, Chicago: Chicago University Press, pp. 232-263.

Garin, Eugenio (1986). L'umanesimo italiano, Roma: Laterza.

Garin, Eugenio (1985). Scienza e vita civile nel Rinascimento italiano, Roma: Laterza.

Hankins, James (2000) (Ed.). Renaissance Civic Humanism, Cambridge: Cambridge University Press.

Hankins, James (2000). "Rhetoric, history and ideology: the civic panegyrics of Leonardo Bruni", In Jamew Hankins (Ed.), Renaissance Civic Humanism, Cambridge: Cambridge University Press, pp. I43-178.

HöRNQVIST, Mikael (2000). "The two myths of civic humanism", In James Hankins (Ed.), Renaissance Civic Humanism. Cambridge: Cambridge University Press, pp. 105-I42. 
Lefort, Claude (1972). Le Travail de l'auvre: Machiavel, Paris: Gallimard.

Lefort, Claude (1976-1977). Curso na EHess, Arquivos Lefort, eHess.

Lefort, Claude (1979). As Formas de História, São Paulo: Brasiliense.

Lefort, Claude (1992). Écrire. À l'épreuve du politique. Paris: Calmann-Levy. Trad. brasileira de Eliana de Melo Souza. Desafios da Escrita Política. São Paulo: Discurso Editorial, 1999.

Lefort, Claude (2007a). Le temps présent. Écrits 1945-2005. Paris: Belin, pp. 217-42I.

Lefort, Claude (2007b). "Entretien avec l'Anti-Mythes". In Le temps présent. Écrits 1945-2005. Paris: Belin, pp. 237-245.

Lefort, Claude (2013). "La construction d'un modèle", L'Histoire, n. 394, Dezembro, p. 62.

SeIgeL, Jerrold (1968). Rhetoric and philosophy in Renaissance humanismm, Princeton: Princeton University Press. 